\title{
Gambaran Kebiasaan Menyirih dan Lesi Mukosa Mulut pada Mahasiswa Papua Di Manado
}

\author{
${ }^{1}$ Vonny N.S. Wowor, ${ }^{1}$ Aurelia Supit, ${ }^{2}$ Dame R. Marbun \\ ${ }^{1}$ Dosen Program Studi Kedokteran Gigi \\ ${ }^{2}$ Mahasiswa Program Studi Kedokteran Gigi \\ Fakultas Kedokteran Universitas Sam Ratulangi
}

\begin{abstract}
ABSTRAK
Kebiasaan menyirih telah dilakukan sejak dahulu kala di Indonesia, khususnya pada suku Papua. Banyak anggapan masyarakat bahwa menyirih dapat menguatkan gigi geligi dan menghambat terjadinya karies, namun dibalik dampak positif dari menyirih ini, ada juga dampak negatifnya berupa timbulnya lesi pada mukosa yang melapisi rongga mulut.

Tujuan penelitian ini yaitu untuk memperoleh gambaran kebiasaan menyirih pada mahasiswa Papua di Kota Manado, mencakup: tujuan menyirih, bahan campuran menyirih, lamanya kebiasaan menyirih, frekuensi menyirih, dan faktor pendorong kebiasaan menyirih serta untuk mengetahui gambaran lesi mukosa mulut pada mahasiswa Papua di Kota Manado.

Jenis penelitian ini yaitu penelitian desktiptif dengan pendekatan cross-sectional study. Teknik pengambilan sampel yang digunakan ialah total sampling dengan jumlah sampel 30 orang. Dari 30 subjek yang diperiksa, sebagian besar merupakan wanita, usia 17-27 tahun. Lamanya menyirih terbanyak 6-10 tahun, dengan frekuensi terbanyak 1-3 kali sehari, bahan campuran menyirih yang paling banyak digunakan ialah campuran sirih, pinang dan kapur. Faktor pendorong utama menyirih yakni karena keinginan sendiri, dimana tujuan menyirih terbanyak yakni agar gigi menjadi kuat dan sehat. Dari 30 subjek ada 29 orang (96,66\%) memiliki lesi dalam rongga mulutnya. Lesi yang diduga sebagai Oral Submucous Fibrosis yakni sebanyak $90 \%$ dan lesi yang diduga sebagai Betel Chewers Mucosa sebanyak 6,66\%.
\end{abstract}

Kata kunci: Kebiasaan menyirih, lesi mukosa mulut, Oral Submucous Fibrosis, Betel Chewer's Mucosa

\begin{abstract}
Betel chewing as a habit has been done since a long time ago in Indonesia, especially in Papua. There are some public perceptions that betel chewing can strengthen teeth and prevent caries. But, behind the positive effect of betel chewing, there are negative effects too, such as the onset of lesions in the oral mucosa.

The purpose of this research is to get an overview of betel chewing habit on Papuan students in Manado, including the purpose of betel chewing, the complete material of betel chewing, duration of betel chewing, frequency of betel chewing, the driving factor of betel chewing, and to get an overview on oral mucosal lesions on Papuan students in Manado.

The type of this research is descriptive research with a cross - sectional study. The sampling technique is total sampling with a sample size of 30 people. The 30 examined subjects, mostly women with age ranging from 17-27 years. The most length of chewing from 6-10 years, with the highest frequency of chewing 1-3 times a day, the average mixture of betel commonly used is betel, areca nut and slaked lime. The major driving factor in betel chewing is their own desire and the most common purpose is to get a strong and healthy teeth. 29 of 30 subjects $(96,66 \%)$ have lesions in the oral cavity. In 90\% of the sample, expected as Oral Submucous Fibrosis and in 6,66\% expected as Betel Chewer's Mucosa.
\end{abstract}

Keyword: Betel chewing habit, oral mucosal lesions, Oral Submucous Fibrosis, Betel Chewer's Mucosa

Korespondensi: Dame R. Marbun, Program Studi Kedokteran Gigi, Fakultas Kedokteran Universitas Sam Ratulangi, Manado, Indonesia. E-mail: dame_marbun@ymail.com 


\section{PENDAHULUAN}

Menyirih merupakan proses meramu campuran dari bahan-bahan seperti sirih, pinang, kapur, gambir, kemudian dikunyah. Kebiasaan ini secara umum dilakukan sejak dahulu kala di wilayah Asia Selatan dan Tenggara serta wilayah Asia Pasifik, demikian juga di antara para imigran di Afrika, Eropa dan Amerika Utara. Di India, kebiasaan mengunyah sirih sudah ada sejak 2000 tahun yang lalu, meskipun tembakau baru diperkenalkan pada abad ke $16 .{ }^{1}$ Di beberapa negara campuran sirih digunakan bersamaan dengan tembakau. Menurut sejarah kuno menyirih dilakukan oleh semua lapisan masyarakat, kelompok usia, termasuk kalangan wanita dan anak-anak, dan di beberapa negara lebih sering terbatas pada kelompok usia lanjut. Menyirih dilakukan dengan cara yang berbeda dari satu negara dengan negara lainnya dan dari satu daerah dengan daerah lainnya dalam satu negara. ${ }^{2,3}$

Di Indonesia khususnya suku Papua, menyirih atau istilahnya "makan pinang" dilakukan sejak Bangsa Melanesia menginjakkan kaki di sekitar kawasan Pasifik. Dalam budaya Papua menyirih juga dijadikan semacam pengantar saat pertemuan adat pernikahan. Di Papua, menyirih dilakukan di semua tempat, di pusat-pusat perkotaan maupun di desadesa. Hampir setiap orang dari pegawai negeri sipil, mahasiswa maupun petugas kesehatan mengonsumsi sirih.

Menyirih juga dilakukan oleh orangorang dari berbagai latar belakang pendidikan, baik dari sekolah dasar hingga perguruan tinggi, seperti pada penelitian yang dilakukan oleh Guo dkk, dengan subjek penelitian yang berasal dari masyarakat Taiwan yang berjumlah 6.203 subjek, dalam penelitian tersebut subjek dengan latar belakang pendidikan perguruan tinggi sebanyak 1.358 subjek yang memiliki kebiasaan menyirih, dari data ini terlihat bahwa orang yang memiliki kebiasaan menyirih juga dari kalangan mahasiswa. $^{5}$

Banyak anggapan masyarakat bahwa menyirih dapat menguatkan gigi geligi dan menghambat terjadinya karies, namun di balik dampak positif dari menyirih ini, ada juga dampak negatifnya berupa timbulnya lesi pada mukosa yang melapisi rongga mulut. Beberapa lesi mukosa mulut yang umum terdapat pada penyirih, yaitu Betel Chewer's Mucosa, Oral Submucous Fibrosis, lesi likenoid, leukoplakia dan kanker rongga mulut. ${ }^{6}$

Menurut penelitian yang dilakukan oleh Hasibuan dkk, dari 98 subjek penelitian yang berasal dari masyarakat Karo, 35 subjek $(35,7 \%)$ di antaranya tidak memperlihatkan adanya lesi di dalam rongga mulut dan 63 subjek $(64,3 \%)$ menunjukkan adanya lesi dalam rongga mulutnya. $^{7}$

Berdasarkan beberapa alasan tersebut di atas, penulis tertarik melakukan penelitian untuk melihat gambaran kebiasaan menyirih serta lesi mukosa mulut pada mahasiswa Papua di Manado.

\section{BAHAN DAN METODE}

Jenis penelitian yang digunakan yaitu survei deskriptif dengan menggunakan pendekatan cross-sectional study, dengan melakukan pengukuran dalam satu waktu. Penelitian ini dilaksanakan di asrama mahasiswa Papua yang berada di Manado.

Populasi dalam penelitian ini merupakan mahasiswa Papua yang berada di asrama di Manado yang mempunyai kebiasaan menyirih sebanyak 30 orang.

Teknik pengambilan sampel yang digunakan dalam penelitian ini yaitu Total sampling. Total sampling adalah teknik pengambilan sampel dimana jumlah sampel sama dengan populasi. Total sampling digunakan karena jumlah populasi yang kurang dari 100, sehingga seluruh populasi dijadikan sampel dalam penelitian. 
Kriteria Inklusi dalam penelitian ini yakni, mahasiswa yang mempunyai kebiasaan menyirih minimal 1 tahun terakhir, mahasiswa yang bersedia dijadikan subjek penelitian dibuktikan dengan penandatanganan informed consent, mahasiswa yang berada di tempat sewaktu penelitian dilaksanakan. Kriteria eksklusi dalam penelitian ini yakni, mahasiswa yang memiliki kebiasaan merokok dan minum minuman beralkohol. Pengambilan data dilakukan dengan cara mendatangi subjek di tiap-tiap asrama. Data demografis berupa umur, jenis kelamin, dan kebiasaan menyirih dilakukan melalui wawancara langsung dan dengan menggunakan kuesioner. Gambaran mengenai lesi yang terdapat di mukosa mulut diperoleh dengan melakukan pemeriksaan langsung dalam rongga mulut, sebelum melakukan pemeriksaan di rongga mulut, terlebih dahulu subjek mengisi informed consent. Pemeriksaan langsung dalam rongga mulut dibantu dengan menggunakan kaca mulut serta senter sebagai alat bantu penerangan.

\section{HASIL PENELITIAN}

1. Karakteristik Responden

Tabel 1. Distribusi responden penelitian berdasarkan tempat tinggal

\begin{tabular}{lcc}
\hline \multicolumn{1}{c}{ Asrama } & Jumlah $(\mathrm{n})$ & Persentase $(\%)$ \\
\hline Merauke & 3 & 10,00 \\
Serui & 2 & 6,67 \\
Biak & 6 & 20,00 \\
Sorong Selatan & 3 & 10,00 \\
Yapen Waropen & 2 & 6,67 \\
Asmat & 1 & 3,32 \\
Moi & 4 & 13,33 \\
Keperawatan Kaimana & 3 & 10,00 \\
Putri Papua & 2 & 6,67 \\
Raja Ampat & 2 & 6,67 \\
Putra Jayapura & 2 & 6,67 \\
\hline Total & 30 & 100 \\
\hline
\end{tabular}

Tabel 2. Distribusi responden menurut jenis kelamin

\begin{tabular}{ccc}
\hline Jenis Kelamin & Jumlah $(\mathrm{n})$ & Persentase $(\%)$ \\
\hline Pria & 8 & 26,67 \\
Wanita & 22 & 73,33 \\
\hline Total & 30 & 100 \\
\hline
\end{tabular}

Tabel 3. Distribusi responden menurut kelompok umur

\begin{tabular}{ccc}
\hline Umur (tahun) & Jumlah (n) & Persentase (\%) \\
\hline $15-21$ & 24 & 80,00 \\
$22-28$ & 6 & 20,00 \\
\hline Total & 30 & 100
\end{tabular}


2. Kebiasaan Menyirih

a. Lamanya menyirih

Tabel 4. Distribusi kebiasaan menyirih menurut lamanya menyirih

\begin{tabular}{lcr}
\hline Lamanya Menyirih & Jumlah (orang) & Persentase $(\%)$ \\
\hline$<1$ tahun & 1 & 3,33 \\
$1-5$ tahun & 7 & 23,34 \\
$6-10$ tahun & 15 & 50,00 \\
$>10$ tahun & 7 & 23,34 \\
\hline \multicolumn{1}{c}{ Total } & 30 & 100
\end{tabular}

b. Frekuensi menyirih

Tabel 5. Distribusi kebiasaan menyirih menurut frekuensinya dalam sehari

\begin{tabular}{lcc}
\hline Frekuensi menyirih & Jumlah (n) & Persentase (\%) \\
\hline $1-3$ kali & 19 & 63,33 \\
$4-5$ kali & 5 & 16,67 \\
$>5$ kali & 6 & 20,00 \\
\hline \multicolumn{1}{c}{ Total } & 30 & 100 \\
\hline
\end{tabular}

b. Bahan campuran menyirih

Tabel 6. Distribusi kebiasaan menyirih menurut bahan campuran yang digunakan

\begin{tabular}{|c|c|c|}
\hline Bahan campuran menyirih & Jumlah (n) & Persentase $(\%)$ \\
\hline Sirih, pinang dan kapur & 27 & 90,00 \\
\hline Sirih, pinang, kapur dan gambir & 1 & 3,33 \\
\hline $\begin{array}{l}\text { Sirih, pinang, gambir, kapur dan } \\
\text { tembakau }\end{array}$ & 2 & 6,67 \\
\hline Total & 30 & 100 \\
\hline
\end{tabular}

c. Faktor pendorong

Tabel 7. Distribusi kebiasaan menyirih menurut faktor pendorongnya

\begin{tabular}{lcc}
\hline Faktor pendorong menyirih & Jumlah (n) & Persentase (\%) \\
\hline Kebiasaan keluarga & 13 & 43,33 \\
Keinginan sendiri & 14 & 46,67 \\
Ajakan teman-teman & 3 & 10,00 \\
Lain-lain & 0 & 0 \\
\hline \multicolumn{1}{c}{ Total } & 30 & 100
\end{tabular}

d. Tujuan menyirih

Tabel 8. Distribusi kebiasaan menyirih menurut tujuannya

\begin{tabular}{lcc}
\hline Tujuan menyirih & Jumlah (n) & Persentase (\%) \\
\hline Menenangkan pikiran & 0 & 0 \\
Agar gigi menjadi kuat dan sehat & 17 & 56,67 \\
Untuk mengurangi rasa sakit gigi & 3 & 10,00 \\
Hanya ikut-ikutan & 10 & 33,33 \\
Lain-lain & 0 & 0 \\
\hline \multicolumn{1}{c}{ Total } & 30 & 100 \\
\hline
\end{tabular}


3. Distribusi Lesi Mukosa Mulut

Tabel 9. Distribusi responden berdasarkan lesi yang terdapat pada rongga mulut

\begin{tabular}{rcc}
\hline \multicolumn{1}{c}{ Lesi } & Jumlah $(\mathrm{n})$ & Persentase $(\%)$ \\
\hline Ada & 29 & 96,66 \\
Tidak ada & 1 & 3,34 \\
\hline Total & 30 & 100 \\
\hline
\end{tabular}

Tabel 10. Distribusi jenis lesi yang terdapat pada rongga mulut

\begin{tabular}{ccc}
\hline Jenis lesi & Jumlah (n) & Persentase (\%) \\
\hline Betel Chewer's Mucosa (BCM) & 2 & 6,66 \\
Oral Submucous Fibrosis (OSF) & 27 & 90,00 \\
\hline Total & 29 & 96,66 \\
\hline
\end{tabular}

Tabel 10 memperlihatkan bahwa OSF merupakan jenis lesi yang paling banyak ditemukan pada responden, yakni sebanyak 27 orang $(90,00 \%)$, sebanyak 2 orang $(6,66 \%)$ memiliki lesi BCM. Kedua jenis lesi dimaksud dapat dilihat pada Gambar 1 dan Gambar 2 di bawah ini:
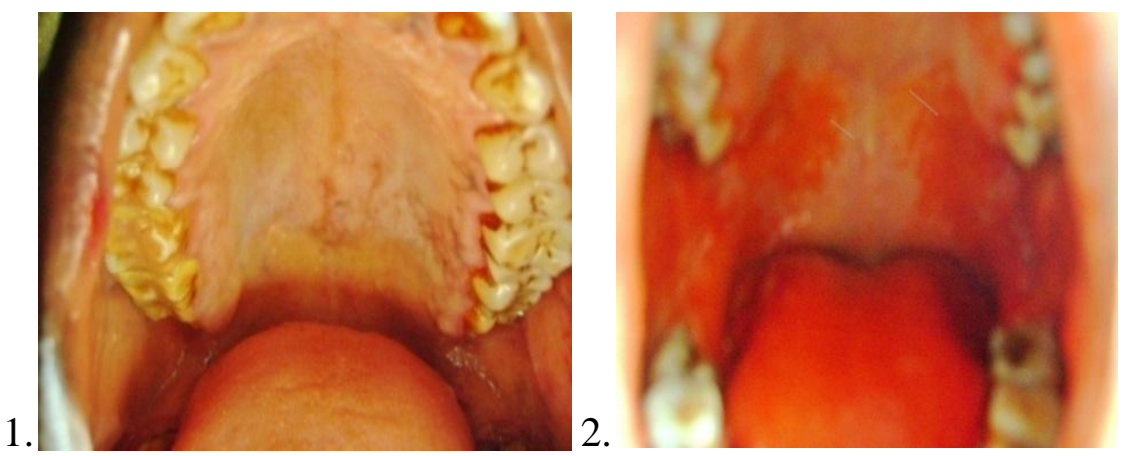

Gambar 1.Lesi yang diduga sebagai Oral Submucous Fibrosis

$\&$ 2. lesi yang diduga sebagai Betel Chewer's Mucosa

\section{Lokasi Lesi}

Lokasi lesi mukosa mulut diperlihatkan pada gambar 13. Lokasi timbulnya lesi OSF paling banyak terdapat pada mukosa pipi yakni pada 27 responden, kemudian diikuti pada palatum, mukosa bibir serta lidah, begitu juga dengan lokasi timbulnya lesi yang diduga sebagai BCM, dari 2 responden yang terdapat lesi BCM di rongga mulutnya, seluruh responden lokasi lesinya terdapat pada mukosa pipi, kemudian 1 responden diantaranya terdapat pada mukosa bibir serta lidah, dan 1 responden lagi terdapat di palatum. Pada penelitian ini didapatkan lokasi timbulnya lesi yang bervariasi, kemungkinan disebabkan karena, setiap responden memiliki cara mengunyah sirih yang berbeda-beda.

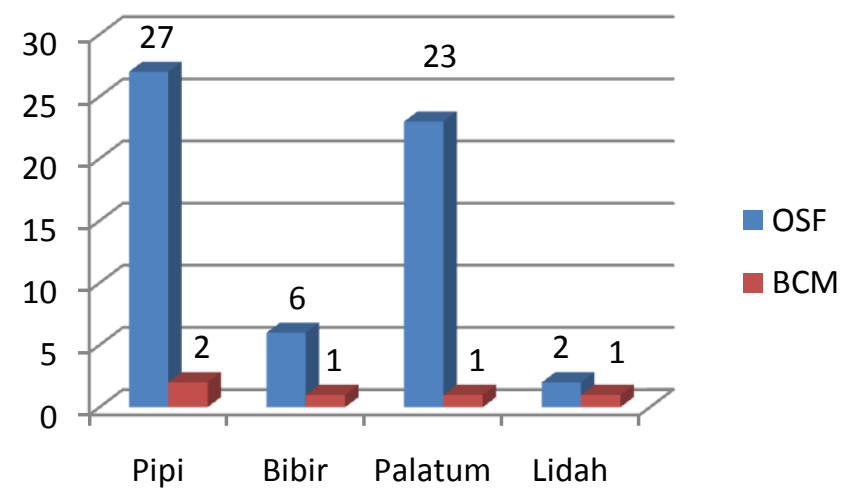

Gambar 3. Lokasi lesi pada penyirih di rongga mulut 


\section{PEMBAHASAN}

Hasil dalam penelitian ini menggambarkan bahwa separuh responden $(50 \%)$, yakni rata-rata menyirih selama 6-10 tahun. Hal ini mungkin disebabkan karena responden merupakan mahasiswa yang masih tergolong dalam kelompok usia remaja hingga dewasa awal, dimana kebiasaan ini umumnya dimulai saat responden duduk di bangku SD. Usia responden paling rendah 17 tahun dan paling tinggi berusia 27 tahun. Pada penelitian yang dilakukan di masyarakat India dengan karakteristik umur responden 14-52 tahun dan memiliki kebiasaan menyirih, ditemukan bahwa kebiasaan menyirih yang dilakukan terbanyak yakni selama 6-10 tahun yang berasal dari responden umur 22-32 tahun. Hasil yang berbeda didapatkan dengan penelitian yang dilakukan oleh Lim pada masyarakat Karo rata-rata didapatkan lamanya kebiasaan menyirih yaitu 2-5 tahun $(43,75 \%){ }^{8} \quad$ Perbedaan hasil ini kemungkinan diakibatkan karena kebiasaan menyirih yang dilakukan oleh masyarakat Karo baru dimulai pada usia dewasa muda.

Hasil penelitian selanjutnya menggambarkan, rata-rata kebiasaan menyirih yang dilakukan responden, yakni dilakukan sebanyak 1-3 kali dalam sehari $(63,33 \%)$. Berbeda dengan hasil yang didapatkan oleh Sembiring dalam penelitiannya pada masyarakat Karo, didapatkan frekuensi menyirih terbanyak dilakukan lebih dari 5 kali dalam sehari $(66,67 \%) .^{9}$ Perbedaan hasil penelitian ini kemungkinan diakibatkan karena bahan campuran menyirih yang digunakan para responden lebih sulit didapatkan di Manado, berbeda dengan di Karo sendiri, bahan campuran menyirih lebih mudah untuk didapatkan.

Hasil penelitian memperlihatkan juga, bahwa campuran menyirih yang paling banyak digunakan responden yakni terdiri dari sirih, pinang dan kapur (90\%). Hal ini terjadi dikarenakan kebiasaan menyirih hanya dilakukan jika bahan campuran menyirih tersedia. Di kota Manado sendiri, bahan campuran menyirih sulit diperoleh, sehingga bahan campuran untuk menyirih tidak terlalu bervariasi. Kondisi ini berbeda halnya dengan di Papua, dimana bahan campuran menyirih lebih mudah untuk didapatkan.

Faktor pendorong terbesar bagi mahasiswa Papua untuk memulai kebiasaan menyirih pertama kali, yakni karena keinginan sendiri $(46,67 \%)$ dan hampir mirip besarnya dengan faktor kebiasaan keluarga (43,33\%). Faktor keinginan sendiri merupakan faktor pendorong terbesar bagi para responden dalam melakukan kebiasaan menyirih. Hal ini mungkin terjadi dikarenakan para responden awalnya hanya ingin mencoba-coba akibat terdorong dari lingkungan keluarganya yang memiliki kebiasaan serupa. Di samping itu pula, kemiripan hasil ini dengan faktor kebiasaan keluarga didapatkan karena responden rata-rata sulit membedakan faktor yang mendorong kebiasaan ini apakah benar-benar murni dari keinginan diri sendiri atau pengaruh dari lingkungan keluarga. Akibatnya hasil yang didapatkan tidak jauh berbeda. Hasil ini hampir sama dengan penelitian yang dilakukan oleh Lim pada masyarakat Karo, didapatkan faktor pendorong kebiasaan menyirih terbanyak yaitu berasal dari keinginan sendiri $(46,87 \%){ }^{8}$

Hasil penelitian tentang kebiasaan menyirih berdasarkan tujuan, menggambarkan bahwa rata-rata tujuan menyirih pada mahasiswa Papua yang ada di Manado yaitu agar gigi menjadi kuat dan sehat $(56,67 \%)$, dan persentase yang memiliki tujuan untuk mengurangi rasa sakit gigi hanya kecil (10\%). Hasil ini berbeda dengan tujuan menyirih 
pada masyarakat Karo yang lebih memilih menyirih untuk tujuan menenangkan pikiran $(50 \%){ }^{8}$ Hal ini terjadi kemungkinan karena pendapat turun-temurun bahwa menyirih dapat menguatkan dan menyehatkan gigi serta para responden juga sudah merasakan sendiri akibat dari kebiasaan menyirih ini yaitu rata-rata gigi para responden tidak ada yang berlubang.

Hasil lainnya yang diperoleh dalam penelitian ini juga memperlihatkan adanya lesi-lesi pada mukosa mulut 29 responden $(96,66 \%)$. Lesi yang diduga sebagai Oral Submucous Fibrosis (OSF) merupakan lesi yang paling banyak ditemukan yaitu pada 27 responden (90\%), sedangkan lesi yang diduga Betel Chewers Mucosa (BCM) ditemukan pada 2 responden $(6,66 \%)$. Penulis berasumsi bahwa lesi yang diduga OSF lebih banyak ditemukan dibandingkan $\mathrm{BCM}$, oleh karena lesi BCM merupakan awal mula timbulnya lesi OSF dan responden umumnya sudah memiliki kebiasaan menyirih cukup lama, yakni sekitar 6-10 tahun. Namun lesi yang diduga OSF pada penelitian ini baru dalam tahap awal, dimana mukosa baru terlihat memucat dan pada beberapa responden terlihat papila di lidah menghilang. Belum terlihat adanya responden yang mengalami kesulitan dalam membuka mulut, dikarenakan lesi yang timbul baru pada tahap awal. Penelitian sejenis yang dilakukan di Bhavnagar, Gujarat, Nagpur, Maharashtra dan New Delhi memperlihatkan gambaran kasus OSF yang hampir serupa jumlahnya, yakni terdapat pada $70 \%$ responden dengan usia di bawah 35 tahun. $^{3}$ Penelitian sejenis yang juga dilakukan oleh Reichart dkk di Thailand, memperlihatkan hasil yang tidak jauh berbeda, dimana prevalensi lesi BCM yang ditemukan sebanyak $13,1 \% .{ }^{10}$ Lesi yang ditemukan pada mukosa mulut mahasiswa Papua ini berkaitan dengan kebiasaan menyirih yang mereka lakukan, juga berkaitan dengan lamanya kebiasaan telah dilakukan, frekuensi kebiasaan ini dilakukan dalam sehari serta berkaitan dengan bahan campuran menyirih yang digunakan. Hal ini mengindikasikan bahwa semakin lama kebiasaan menyirih dilakukan, semakin tinggi frekuensi kebiasaan ini dilakukan dalam sehari dan semakin sering rongga mulut terpapar dengan bahan campuran menyirih maka semakin tinggi pula resiko seseorang terkena lesi akibat kebiasaan menyirih tersebut.

\section{SIMPULAN}

1. Pada penelitian ini, diperoleh gambaran kebiasaan menyirih pada mahasiswa Papua di kota Manado yakni:
a. Kebiasaan menyirih paling banyak bertujuan agar gigi menjadi kuat dan sehat.

b. Bahan campuran yang paling banyak digunakan dalam menyirih terdiri dari campuran sirih, pinang dan kapur.
c. Lamanya kebiasaan menyirih rata-rata dalam kurun waktu 6-10 tahun.
d. Frekuensi menyirih rata-rata 1-3 kali dalam sehari.
e. Faktor pendorong terbesar kebiasaan menyirih berasal dari keinginan diri sendiri.

2. Gambaran lesi mukosa mulut yang ditemukan pada mahasiswa Papua yang memiliki kebiasaan menyirih di kota Manado, yakni:
a. Lesi yang diduga Oral
Submucous Fibrosis merupakan lesi yang paling banyak ditemukan dalam rongga mulut, yakni sebanyak $90 \%$, lesi yang 
diduga sebagai Betel Chewer's Mucosa sebanyak 6,66\%.

b. Lokasi lesi yang ditemukan di dalam rongga mulut responden paling banyak pada mukosa pipi kemudian diikuti pada palatum, lidah kemudian pada mukosa bibir.

\section{SARAN}

Diharapkan para tenaga kesehatan perlu melakukan penyuluhan kepada masyarakat yang memiliki kebiasaan menyirih tentang efek samping dari kebiasaan menyirih tersebut, sehingga para penyirih dapat mengurangi frekuensi menyirih sehingga dapat terhindar dari dampak buruk kebiasaan menyirih. Diperlukan penelitian lebih lanjut dengan menggunakan pemeriksaan penunjang seperti pemeriksaan histopatologi sehingga lesi yang ditemukan dapat ditegakkan diagnosanya secara pasti demikian halnya dengan lesi-lesi yang lain sebagai akibat kebiasaan menyirih.

\section{DAFTAR PUSTAKA}

1. Gandhi G, Kaur R, Sharma S. Chewing pan masala and/or betel quid-fashionable attributes and/or cancer menaces. Journal of Human Ecology 2005;17(3):161-6.

2. Flora MS, Mascie-Taylor GNC, Rahman M. Betel quid chewing and its risk factors in Bangladeshi adults. WHO South-East Asia Journal of Public Health 2012;1(2):169-81.

3. Gupta PC, Ray CS. Epidemiology of betel quid usage. Ann Acad Med Singapore 2004;33 suppl:31S-6S.

4. Jayapura kota seribu pinang. Tabloid Jubi. [Online] 08 Maret 2013. Available from: URL: http://cloud.papua.go.id/id/budaya/a rtikel/Pages/ JAYAPURA,-KOTA-
SERIBU-PINANG.aspx (13 April 2013)

5. Guo SE, Huang TJ, Huang JC, Lin MS, Hong RM, Chang $\mathrm{CH}$ et al. Alcohol, betel-nut and cigarette consumption are negatively associated with health promoting behaviors in Taiwan: A crosssectional study. BMC Public Health 2013;13:2-3.

6. Trivedy CR, Craig G, Warnakulasuriya S. The oral health consequences of chewing areca nut. Addiction Biology 2002;7:115-25.

7. Hasibuan S, Permana G, Aliyah S. Mukosa mulut yang dihubungkan dengan kebiasaan menyirih dikalangan penduduk tanah Karo Sumatera Utara. Dentika Dental Journal 2003;8:67-74.

8. Lim E. Kebiasaan mengunyah sirih dan lesi yang dijumpai pada mukosa oral masyarakat Batak Karo. Skripsi, Medan: FKG USU, 2007. h.23-9.

9. Sembiring RS. Penelitian tentang kebiasaan mengunyah sirih dan hubungannya dengan indeks penyakit periodontal pada wanita di Kecamatan Lau Baleng Kabipaten Karo. Skripsi, Medan: FKG USU, 2003. h.19-21.

10. Reichart PS, Schinidtberg W, Scheifele CH. Betel chewer's mucosa in elderly cambodian women. J Oral Pathol Med 1996; 367-70. 